Original Article

\title{
Prognostic value of worsening renal function in outpatients with chronic heart failure
}

\author{
Rodrigo Pimentel a , Marta Couto a, Olga Laszczyńska ${ }^{\text {b,c }}$, Fernando Friões ${ }^{\text {a }}$, Paulo Bettencourt a , Ana Azevedo b,c,* \\ a Department of Internal Medicine, Centro Hospitalar de São João, EPE, Porto, Portugal \\ b Department of Clinical Epidemiology, Predictive Medicine and Public Health, University of Porto Medical School, Porto, Portugal \\ ${ }^{\mathrm{c}}$ Institute of Public Health of the University of Porto (ISPUP), Porto, Portugal
}

\section{A R T I C L E I N F O}

\section{Article history:}

Received 30 October 2013

Received in revised form 30 May 2014

Accepted 4 June 2014

Available online 27 June 2014

Keywords:

Heart failure

Cardio-renal syndrome

Worsening renal function

Prognosis

\begin{abstract}
A B S T R A C T
Introduction and objectives: Renal function impairment predicts poor survival in heart failure. Attention has recently shifted to worsening renal function, based mostly on serum creatinine and estimated glomerular filtration rate. We assessed the prognostic effect of worsening renal function in ambulatory heart failure patients. Methods: Data from 306 ambulatory patients were abstracted from medical files. Worsening renal function was based on the change in estimated glomerular filtration rate, serum creatinine and urea within 6 months of referral. Prognosis was assessed by the composite endpoint all-cause death or heart failure hospitalization, censored at 2 years. Hazard ratios were estimated for worsening renal function, adjusted for sex, age, diabetes, New York Heart Association class, left ventricular systolic dysfunction, medications and baseline renal function.

Results: The agreement among definitions was fair, with kappa coefficients generally not surpassing 0.5. Worsening renal function was associated with poor outcome with adjusted hazard ratios ( $95 \%$ confidence interval) of 3.2 (1.8-5.9) for an increase of serum creatinine $>0.3 \mathrm{mg} / \mathrm{dl} ; 2.2$ (1.3-3.7) for an increase in serum urea $>20 \mathrm{mg} / \mathrm{dl}$ and 1.9 (1.1-3.3) for a decrease in estimated glomerular filtration rate $>20 \%$, independent of baseline renal function. The 2-year risk of death/heart failure hospitalization was approximately $50 \%$ in patients with an increase in serum creatinine or in serum urea; this positive predictive value was higher than for decreasing estimated glomerular filtration rate.

Conclusions: In conclusion, worsening renal function was significantly associated with a worse outcome. Different definitions identified different patients at risk and increasing creatinine/urea performed better than decreasing estimated glomerular filtration rate.
\end{abstract}

(C) 2014 European Federation of Internal Medicine. Published by Elsevier B.V. All rights reserved.

\section{Introduction}

Renal function impairment is common in patients with both acute and chronic heart failure (HF). A variety of mechanisms can contribute to a reduction in glomerular filtration rate in patients with $\mathrm{HF}$, including neurohumoral adaptations, reduced renal perfusion, increased renal venous pressure and right ventricular dysfunction [1,2]. Likewise, both acute kidney injury and chronic kidney disease may result in cardiac injury or dysfunction $[3,4]$. Also, comorbidities such as diabetes mellitus and drugs used in HF affect renal function [5,6].

Impairment of renal function has long been identified as a prominent predictor of poor survival and a higher risk of hospitalization in HF patients [7,8]. Most previous studies have focused on serum

Abbreviations: $\mathrm{CI}$, Confidence interval; eGFR, Estimated glomerular filtration rate; $\mathrm{HF}$ Heart failure; HR, Hazard ratio; NYHA, New York Heart Association; WRF, Worsening renal function.

* Corresponding author at: Department of Clinical Epidemiology, Predictive Medicine and Public Health, University of Porto Medical School, Alameda Prof. Hernâni Monteiro, 4200-319 Porto, Portugal. Tel.: + 351225513 652; fax: + 351225513653

E-mail address: anazev@med.up.pt (A. Azevedo). creatinine and glomerular filtration rate estimating equations as markers of renal dysfunction $[9,10]$. These equations, like the Modification of Diet in Renal Disease equation, improve upon serum creatinine by incorporating known demographic and clinical variables as observed surrogates for the unmeasured physiological factors other than glomerular filtration rate that affects the serum creatinine concentration, such as generation and tubular secretion [11]. However, there is growing evidence that other blood markers of renal dysfunction, such as serum urea, may be superior to creatinine when it comes to predicting prognosis in patients with HF [12-14]. Blood urea concentration reflects a constellation of renal dysfunction, diuretic resistance and cachexia rather than just the glomerular filtration rate [9].

Attention has recently shifted to the adverse prognosis, reflected in increased length of stay, readmission rate, and short- and long-term mortality, associated with worsening renal function (WRF) [15-17]. Some authors argue that WRF, defined by an absolute increase in creatinine, is biased by baseline renal function and that an alternative definition should be considered [18].

Our objective was to assess the effect of WRF in ambulatory HF patients on long-term all-cause death and hospital admission for HF, 
using different markers/definitions of WRF and accounting for potential confounders.

\section{Methods}

\subsection{Study design and sample selection}

We conducted a retrospective cohort study on ambulatory patients attending an outpatient clinic especially dedicated to the care of HF patients, at Hospital de São João, a public tertiary care academic hospital. We screened files of patients consecutively referred to the clinic from January 2000 to July 2011 and who had at least 2 appointments (Fig. 1). Patients were eligible if they had a confirmed diagnosis of HF according to the European Society of Cardiology criteria [7], with a history of left ventricular systolic dysfunction, and follow-up at the clinic for at least the first 6 months, excluding patients under renal replacement therapy before the baseline.

From 363 eligible patients, 57 (15.7\%) were excluded because there were no laboratory results available at the hospital's laboratory information system in the first four months after referral to the clinic $(\mathrm{n}=11)$ or there were no laboratory results at $6( \pm 3)$ months $(n=14)$ or data on key variables for analysis were missing $(n=32)$ (Fig. 1$)$. These 57 patients did not differ significantly from the 306 patients with complete data for analysis regarding gender (men: $63.2 \%$ vs. $63.1 \%, \mathrm{p}=0.99$ ), age (mean: 66.9 vs. 67.1 years, $\mathrm{p}=0.98$ ), presence of diabetes mellitus ( $40.4 \%$ vs. $37.6 \%, p=0.69$ ), estimated glomerular filtration rate (eGFR) at baseline $<60 \mathrm{ml} / \mathrm{min}(38.8 \%$ vs. $45.4 \%, \mathrm{p}=0.38)$, serum creatinine at baseline $\geq 1.5 \mathrm{mg} / \mathrm{dl}$ ( $16.3 \%$ vs. $19.0 \%, \mathrm{p}=0.66$ ), serum urea at baseline $\geq 60 \mathrm{mg} / \mathrm{dl}$ ( $36.7 \%$ vs. $42.8 \%, \mathrm{p}=0.42$ ) or risk of death or HF hospitalization ( $23 \%$ vs. $17 \%$ at 1 year and $40 \%$ vs. $32 \%$ at 2 years, $p=0.25$ ).

The study protocol conforms to the ethical guidelines of the Declaration of Helsinki and it was approved by the institution's ethics committee.

\subsection{Data extraction}

Data were extracted from the patients' clinical files, by one trained data extractor, using standardized procedures and a form designed for this purpose. We used all available data from electronic and paper files. For a long time during the study period, it was a standard practice at the echocardiography laboratory to report only a semi-quantitative classification of systolic dysfunction; severe left ventricular systolic dysfunction is usually considered to correspond to an ejection fraction below $30 \%$ and this cut-off was used in this study when ejection fraction was available.

We transformed daily angiotensin converting enzyme-inhibitor or angiotensin II receptor blocker dose into a single variable considering equivalent doses of lisinopril, assuming the proportion of the target dose established in clinical trials as the conversion unit (lisinopril $20 \mathrm{mg}=$ captopril $150 \mathrm{mg}=$ enalapril $20 \mathrm{mg}=$ ramipril $5 \mathrm{mg}=$ trandolapril $4 \mathrm{mg}=$ perindopril $10 \mathrm{mg}=$ fosinopril $20 \mathrm{mg}=$ losartan $100 \mathrm{mg}=$ candesartan $32 \mathrm{mg}=$ valsartan $160 \mathrm{mg}$ ).

The primary outcome of interest was all-cause death or hospitalization due to HF. For ascertainment of the occurrence of the outcome, we relied on all data available in the hospital file, whether from the HF clinic or other specialties. Any hospitalization, appointment or procedure in any specialty was considered evidence of being alive. It is a standard procedure at the clinic to contact patients or next-of-kin to ascertain vital status when patients miss appointments. In this population, it is exceptional for patients to be hospitalized in other institutions and, when this happens, those events are communicated to the clinic through a copy of the discharge note.

We considered all-cause death as an endpoint due to the difficulty in assuring the quality of classification when considering cause-specific deaths, particularly in elderly patients. For hospitalizations, the clinical diagnosis at the discharge note was considered.

\subsection{Criteria to define worsening renal function}

Three laboratory parameters were used: an estimate of the glomerular filtration rate based on the Modification of Diet in Renal Disease equation, serum creatinine and serum urea. Each parameter was categorized according to the change in the parameter's value from baseline to 6 months surpassing a 20\% decrease of the baseline value of the eGFR or an absolute increase over $0.3 \mathrm{mg} / \mathrm{dl}$ of serum creatinine or $20 \mathrm{mg} / \mathrm{dl}$ of urea.

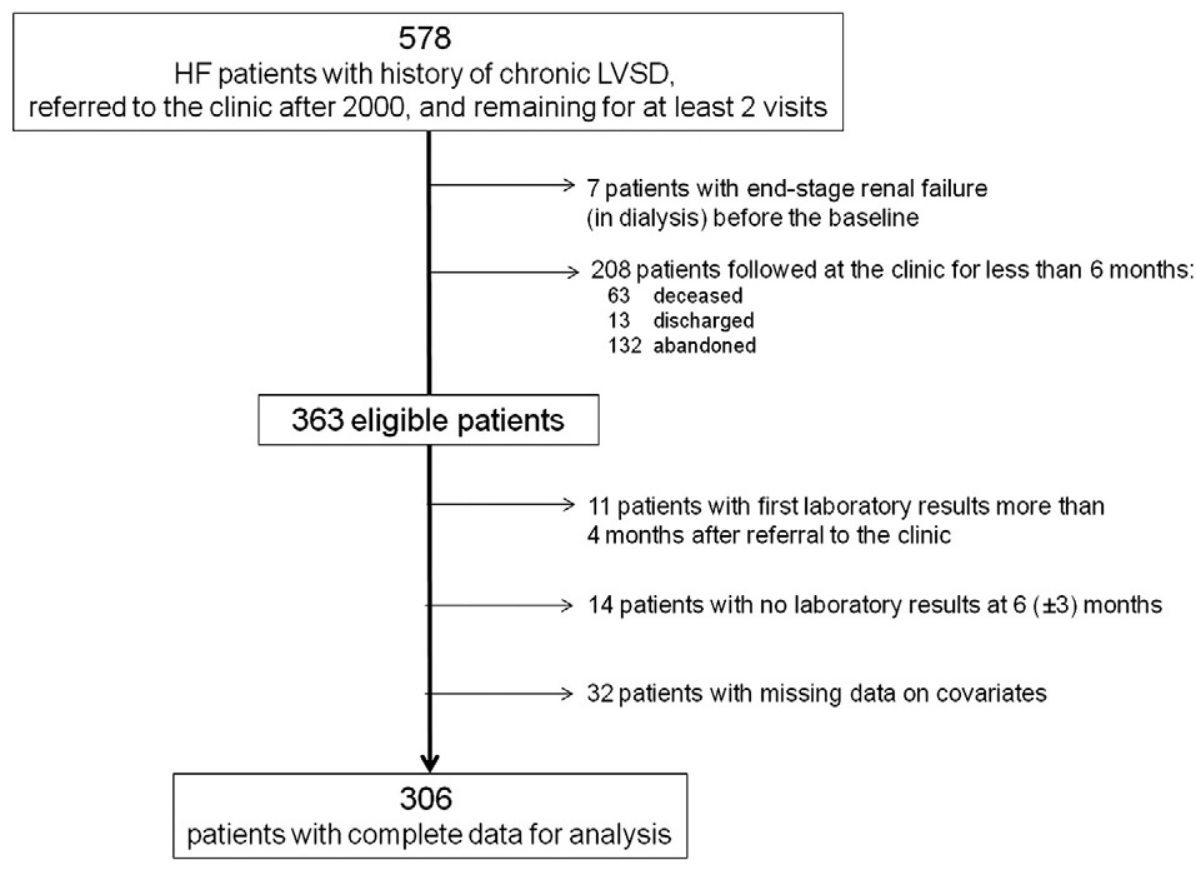

Fig. 1. Study design and sample selection. HF, heart failure; LVSD, left ventricular systolic dysfunction. 


\subsection{Statistical analysis}

We used survival analysis to estimate hospitalization-free survival after the 6 month visit and its association with WRF indicators. Data was censored at 2 years. The median follow-up of censored patients was 730 days and $75 \%$ of patients were followed for more than 1 year. Kaplan-Meier survival estimates were compared among categories of WRF and are represented graphically. Cox proportional hazards regression models were used to quantify the association between each tested WRF measure and the outcome. Covariates included in the multivariate models were decided a priori based on the previous knowledge: sex, age, diabetes mellitus, New York Heart Association (NYHA) class at 6 months, daily furosemide dose at 6 months, daily angiotensin conversion enzyme inhibitor/angiotensin II receptor blocker dose, betablocker use at 6 months and severe (versus mild-moderate) left ventricular systolic dysfunction. Prognosis-modifying variables that may change over time, such as NYHA class and therapy, were considered in the analysis as their value at 6 months since this was the baseline point to quantify prognosis.

For all analyses, a p value below 0.05 was considered statistically significant. A sample size calculation was not done a priori because the study was not designed on purpose for this objective. A power calculation showed that, for the number of unexposed (no worsening renal function) and exposed (worsening renal function) patients analyzed, and considering the 2-year risk of the primary endpoint observed among unexposed patients (20 to 30\%), the statistical power to detect a relative risk of 2 as significant was $>94 \%$ for definitions based on a 6 month variation of eGFR (decrease $20 \%$ ), creatinine (increase $0.3 \mathrm{mg} / \mathrm{dl}$ ) and urea (increase $20 \mathrm{mg} / \mathrm{dl}$ ). Analyses were run in Stata version 11.1 for Windows (StataCorp LP, College Station, TX).

\section{Results}

\subsection{Baseline characteristics}

Baseline patient characteristics by status of WRF are summarized in Table 2. The mean age of patients was $67.0 \pm 13.6$ years and $63.1 \%$ were male. Most had severe left ventricular systolic dysfunction (66.0\%), although $89.3 \%$ were in class I/II NYHA. Most patients were taking angiotensin converting enzyme inhibitors/angiotensin II receptor blockers (94.4\%; 35.6\% on target dose) and beta-blockers (88.6\%) at 6 months. All were taking loop diuretics and $38.6 \%$ were under spironolactone. The mean eGFR was $63.2 \pm 21.5 \mathrm{ml} / \mathrm{min} / 1.73 \mathrm{~m}^{2}$. In our study sample, there were 66 patients (21.6\%) and 4 patients (1.3\%) with hospitalization due to heart failure within one month before the starting point and the 6-month observation point, respectively. (See Table 1.)

Patients with WRF, whatever definition considered, were more often female and diabetic, although the difference in the prevalence of diabetes only reached statistical significance for increasing serum creatinine; patients with an increase in urea of at least $20 \mathrm{mg} / \mathrm{dl}$ were older and under higher dose of loop diuretics, whereas those with increasing serum creatinine or decreasing eGFR were medicated with a higher dose of renin-angiotensin system inhibitors.

Table 1

Definitions of worsening renal function.

\begin{tabular}{ll}
\hline & 6-month variation \\
\hline eGFR (MDRD) & $\downarrow 20 \%$ of the baseline value \\
Serum creatinine & $\uparrow 0.3 \mathrm{mg} / \mathrm{dl}$ (absolute) \\
Serum urea & $\uparrow 20 \mathrm{mg} / \mathrm{dl}$ (absolute) \\
\hline
\end{tabular}

eGFR - estimated glomerular filtration rate; MDRD - Modification of Diet in Renal Disease.

\subsection{WRF incidence}

A drop in eGFR by more than $20 \%$ from baseline occurred in $18.0 \%$ of the patients. An increase of serum creatinine by more than $0.3 \mathrm{mg} / \mathrm{dl}$ affected $15.7 \%$ of patients, whereas an increase in urea by more than $20 \mathrm{mg} / \mathrm{dl}$ was observed in $17.7 \%$ of patients (Table 3 ).

When using the different definitions, different patients were identified as having WRF, with kappa coefficients for the concordance not surpassing 0.5 , except between the 6 -month variation in eGFR $(>20 \%)$ and in serum creatinine $(>0.3 \mathrm{mg} / \mathrm{dl})$ which was $\mathrm{k}=0.8$.

\subsection{WRF and outcomes}

Of the 306 patients, $82.9 \%$ (95\% confidence interval (CI): 77.9-86.8\%) and $68.3 \%$ (95\% CI: 62.1-73.8\%) were alive and free from hospitalization for HF at 1 and 2 years, respectively.

When analyzing Kaplan-Meier survival estimates (Fig. 2), patients with WRF, whatever definition considered, had poorer survival compared to those with improved or stable renal function.

An increase in serum urea by more than $20 \mathrm{mg} / \mathrm{dl}$ or an increase in serum creatinine by more than $0.3 \mathrm{mg} / \mathrm{dl}$ at 6 months conferred higher risk of death or HF hospitalization within 2 years ( $54.8 \%$ and $48.9 \%$, respectively) than 6 -month decrease by more than $20 \%$ in eGFR (42.1\%) (Table 3).

WRF defined as an increase of serum creatinine by more than $0.3 \mathrm{mg} / \mathrm{dl}$ tripled the risk of death/hospitalization (adjusted HR: 3.2, 95\% CI: 1.8-5.8), while an increase of serum urea by more than $20 \mathrm{mg} / \mathrm{dl}$ or a decrease in eGFR more than 20\% doubled it (adjusted HR: 2.2, 95\% CI: 1.3-3.8; 1.8, 95\% CI: 1.1-3.2, respectively).

After adjusting for renal function at baseline, the risk of death/ hospitalization conferred by WRF was maintained in all categories of change in renal function (Table 3 ). In sensitivity analysis, patients with HF hospitalization within 1 month preceding the baseline and the 6-month assessment point were excluded. The estimates of WRF prognostic role in restricted sample were stronger than those of the whole sample (Table 3).

\section{Discussion}

Depending on the definition used, WRF incidence within 6 months of referral to the clinic varied from $15.7 \%$ (increase by more than $0.3 \mathrm{mg} / \mathrm{dl}$ in serum creatinine) to $18.0 \%$ (eGFR decrease more than $20 \%$ from baseline), with low concordance among the several criteria, in our HF ambulatory patients. Independently of the definition used, WRF had a significantly worse survival, with an increased risk of all cause death and hospital admission for HF after adjusting for age, comorbidities, left ventricular systolic dysfunction, NYHA class, medications and baseline renal function. The association with prognosis was stronger when defining WRF based on either serum creatinine or urea, instead of using the eGFR, when stratifying by the cut-offs used in this study. The 2-year risk of death/HF hospitalization was approximately $50 \%$ in patients with an increase in serum creatinine or in serum urea; this being the highest positive predictive value in terms of HF prognosis.

Although the relationship between WRF and survival in chronic HF has already been reported in several multi-center studies $[5,16,19,20]$, our study reinforces this association in ambulatory patients, a population less studied. The definitions we used, based either on eGFR, creatinine or urea, were arbitrary but followed previous studies [5,12-14,16, 19,20 ], which contributes to comparability and supports the generalizability of its predictive value. Despite the recently proposed new classification of cardio-renal syndromes, the precise mechanism by which impaired baseline renal function and WRF exert adverse prognostic effects remains unclear [15]. WRF may be a final clinical pathway and that prognostic significance may vary by specific causal mechanism of renal insult. Various patterns of WRF may have different prognostic implications and may require different therapeutic approaches. Transient 
Table 2

Patient characteristics by status of worsening renal function.

\begin{tabular}{|c|c|c|c|c|c|c|c|}
\hline \multirow[b]{3}{*}{$\mathrm{N}$} & \multirow{3}{*}{$\begin{array}{l}\text { All } \\
306\end{array}$} & \multicolumn{2}{|c|}{ 6-month variation in eGFR (MDRD) } & \multicolumn{2}{|c|}{ 6-month variation in serum creatinine } & \multicolumn{2}{|c|}{ 6-month variation in serum urea } \\
\hline & & $\begin{array}{l}\text { Increase or no change } \\
\text { up to } 20 \%\end{array}$ & $\begin{array}{l}\text { Decrease more } \\
\text { than } 20 \%\end{array}$ & $\begin{array}{l}\text { Decrease or no change } \\
\text { up to } 0.3 \mathrm{mg} / \mathrm{dl} \text { increase }\end{array}$ & $\begin{array}{l}\text { Increase by more } \\
\text { than } 0.3 \mathrm{mg} / \mathrm{dl}\end{array}$ & $\begin{array}{l}\text { Decrease or no change } \\
\text { up to } 20 \mathrm{mg} / \mathrm{dl} \text { increase }\end{array}$ & $\begin{array}{l}\text { Increase by more } \\
\text { than } 20 \mathrm{mg} / \mathrm{dl}\end{array}$ \\
\hline & & 251 & 55 & 258 & 48 & 252 & 54 \\
\hline \multicolumn{8}{|l|}{ Demographic } \\
\hline Age (years), mean $\pm S D$ & $67.0 \pm 13.6$ & $67.0 \pm 13.7$ & $67.5 \pm 13.3$ & $66.7 \pm 13.6$ & $69.2 \pm 13.2$ & $66.0 \pm 13.6$ & $72.4 \pm 12.4^{c}$ \\
\hline Female sex, $\mathrm{n}(\%)$ & $113(36.9)$ & $85(33.9)$ & $28(50.9)^{\mathrm{a}}$ & $88(34.1)$ & $25(52.1)^{\mathrm{a}}$ & $86(34.1)$ & $27(50.0)^{\mathrm{a}}$ \\
\hline \multicolumn{8}{|l|}{ Medical history } \\
\hline Diabetes mellitus, n (\%) & $115(37.6)$ & $89(35.5)$ & $26(47.3)$ & $91(35.3)$ & $24(50)^{\mathrm{a}}$ & $89(35.3)$ & $26(48.2)$ \\
\hline Hypertension, $\mathrm{n}(\%)$ & 195 (63.7) & $160(63.8)$ & $35(63.6)$ & $163(63.2)$ & $32(66.7)$ & $158(62.7)$ & $37(68.5)$ \\
\hline Atrial fibrillation, $\mathrm{n}(\%)$ & $128(41.8)$ & $107(42.6)$ & $21(38.2)$ & $110(42.6)$ & $18(37.5)$ & $109(43.3)$ & $19(35.2)$ \\
\hline \multicolumn{8}{|l|}{ HF etiology } \\
\hline Ischemic HF, n (\%) & $131(42.8)$ & $109(43.4)$ & $22(40.0)$ & $110(42.6)$ & $21(43.8)$ & $105(41.7)$ & $26(48.2)$ \\
\hline \multirow{2}{*}{\multicolumn{8}{|c|}{ Medication at 6 months }} \\
\hline & & & & & & & \\
\hline$\leq 60 \mathrm{mg}$ & $131(42.8)$ & $110(43.8)$ & $21(38.2)$ & $117(45.3)$ & $14(29.2)$ & $118(46.8)$ & $13(24.1)$ \\
\hline $61-120 \mathrm{mg}$ & $133(43.5)$ & $106(42.2)$ & $27(49.1)$ & $106(41.1)$ & $27(56.2)$ & $106(42.1)$ & $27(50.0)$ \\
\hline$>120 \mathrm{mg}$ & $42(13.7)$ & 35 (13.9) & $7(12.7)$ & $35(13.6)$ & $7(14.6)$ & $28(11.1)$ & $14(25.9)^{\mathrm{c}}$ \\
\hline \multicolumn{8}{|l|}{ ACEIs/ARBs dose, $n(\%)$} \\
\hline $0 \mathrm{mg}$ & $17(5.6)$ & $16(6.4)$ & $1(1.8)$ & $13(5.0)$ & $4(8.3)$ & $14(5.6)$ & $3(5.6)$ \\
\hline $2.5-10 \mathrm{mg}$ & $180(58.8)$ & $155(61.8)$ & $25(45.5)$ & $162(62.8)$ & $18(37.5)$ & $148(58.7)$ & $32(59.7)$ \\
\hline$\geq 20 \mathrm{mg}$ & $109(35.6)$ & $80(31.9)$ & $29(52.7)^{\mathrm{b}}$ & $83(32.1)$ & $26(54.2)^{\mathrm{b}}$ & $90(35.7)$ & $19(35.2)$ \\
\hline Beta-blocker, n (\%) & $271(88.6)$ & $222(88.5)$ & $49(89.1)$ & $227(88.0)$ & $44(91.7)$ & $225(89.3)$ & $46(85.2)$ \\
\hline Spironolactone, $\mathrm{n}(\%)$ & $118(38.6)$ & $96(38.3)$ & $22(40.0)$ & $100(38.8)$ & $18(37.5)$ & $98(38.9)$ & $20(37.0)$ \\
\hline \multirow{2}{*}{\multicolumn{8}{|c|}{$\begin{array}{l}\text { Functional status } \\
\text { NYHA class, n (\%) }\end{array}$}} \\
\hline & & & & & & & \\
\hline I & $110(36.0)$ & $88(35.1)$ & $22(40.0)$ & $90(34.9)$ & $20(41.7)$ & $96(38.1)$ & $14(25.9)$ \\
\hline II & $163(53.3)$ & $133(53.0)$ & $30(54.6)$ & $137(53.1)$ & $26(54.2)$ & $132(52.4)$ & $31(57.4)$ \\
\hline III & $33(10.8)$ & $30(12.0)$ & $3(5.5)$ & $31(12.0)$ & $2(4.2)$ & $24(9.5)$ & $9(16.7)$ \\
\hline Severe LVSD, n (\%) & $202(66.0)$ & $167(66.5)$ & $35(63.6)$ & $171(66.3)$ & $31(64.6)$ & $164(65.1)$ & $38(70.4)$ \\
\hline
\end{tabular}

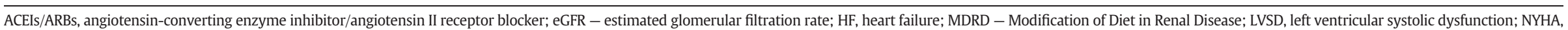
New York Heart Association; SD, standard deviation.

Comparison between patients with and without WRF: ${ }^{\mathrm{a}} \mathrm{p} \leq 0.05$; $^{\mathrm{b}} \mathrm{p} \leq 0.01$; ${ }^{\mathrm{c}} \mathrm{p} \leq 0.001$ 
Table 3

Prevalence of categories of change in renal function within 6 months of referral and association with the risk of death or hospital admission for heart failure up to 2 years later.

\begin{tabular}{|c|c|c|c|c|c|c|c|}
\hline & \multirow{2}{*}{$\begin{array}{l}\text { Prevalence } \\
\mathrm{n}(\%)\end{array}$} & \multicolumn{2}{|c|}{$\begin{array}{l}\text { Risk of death or HF } \\
\text { hospitalization }\end{array}$} & \multicolumn{4}{|l|}{$\mathrm{HR}(95 \% \mathrm{CI})$} \\
\hline & & 2-year risk (\%) & p-Value & Crude & Adjusted $^{\mathrm{a}}$ & Adjusted $^{\mathrm{b}}$ & Adjusted $^{\mathrm{C}}$ \\
\hline 6-month variation in eGFR (MDRD) & & & 0.07 & & & & \\
\hline Increase or no change up to $20 \%$ decrease & $251(82.0)$ & 29.2 & & 1 & 1 & 1 & 1 \\
\hline Decrease more than $20 \%$ of baseline & $55(18.0)$ & 42.1 & & $1.6(1.0-2.7)$ & $1.8(1.1-3.2)$ & $1.9(1.1-3.3)$ & $2.3(1.1-4.6)$ \\
\hline 6-month variation in serum creatinine & & & 0.003 & & & & \\
\hline Decrease or no change up to $0.3 \mathrm{mg} / \mathrm{dl}$ increase & $258(84.3)$ & 28.4 & & 1 & 1 & 1 & 1 \\
\hline Increase by more than $0.3 \mathrm{mg} / \mathrm{dl}$ & $48(15.7)$ & 48.9 & & $2.1(1.3-3.5)$ & $3.2(1.8-5.8)$ & $3.2(1.8-5.9)$ & $4.2(2.1-8.7)$ \\
\hline 6-month variation in serum urea & & & $<0.001$ & & & & \\
\hline Decrease or no change up to $20 \mathrm{mg} / \mathrm{dl}$ increase & $252(82.4)$ & 27.3 & & 1 & 1 & 1 & 1 \\
\hline Increase by more than $20 \mathrm{mg} / \mathrm{dl}$ & $54(17.7)$ & 54.8 & & $2.8(1.7-4.6)$ & $2.2(1.3-3.8)$ & $2.2(1.3-3.7)$ & $3.5(1.8-6.7)$ \\
\hline
\end{tabular}

95\% CI, 95\% confidence interval; eGFR, estimated glomerular filtration rate; HR, hazard ratio; HF, heart failure; MDRD, Modification of Diet in Renal Disease.

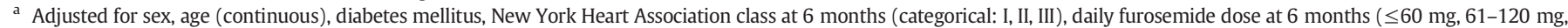

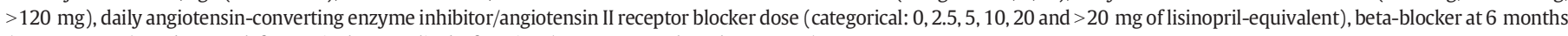
(no versus yes), and severe left ventricular systolic dysfunction (severe versus less than severe).

b Adjusted additionally for renal function at baseline: baseline eGFR ( $<\mathrm{vs} \geq 60 \mathrm{ml} / \mathrm{min}$ ) when assessing the effect of change in eGFR; baseline serum creatinine ( $<\mathrm{vs} \geq 1.5 \mathrm{mg} / \mathrm{dl}$ ) when assessing the effect of change in serum creatinine; baseline serum urea ( $<\mathrm{vs} \geq 60 \mathrm{mg} / \mathrm{dl}$ ) when assessing the effect of change in serum urea.

c Sensitivity analysis: adjusted for all confounders and baseline renal function, after excluding patients with a hospitalization for heart failure decompensation in the month before the baseline evaluation and the 6-month evaluation.

WRF may reflect short-term alterations in fluid status (like short-term dehydration), associated with successful treatment of congestion, and may not be associated with poor outcome. Since a possible transient renal dysfunction associated with heart failure decompensation was much more likely at the starting point than at 6 months, we expected that we could have overestimated the number of patients whose renal function improved over 6 months, leading to an attenuation of the effect of worsening renal function, which was even stronger after excluding patients with a recent decompensation. In contrast, persistent WRF may occur in patients with more severe HF, neurohumoral activation, and hemodynamic abnormalities, which are associated with a worse prognosis [21]. It may also limit the use of prognosis-modifying therapy, like angiotensin-converting enzyme inhibitors, angiotensin receptor blockers and beta-blockers.

In previous studies, urea performed better than creatinine in predicting prognosis in patients with HF $[9,12,13]$. Similarly, in our study, having an increase in serum urea by more than $20 \mathrm{mg} / \mathrm{dl}$ conveyed the worst prognosis of all. Urea reflects more than just GFR, being also a marker of renal tubular reabsorption (50\% is reabsorbed in renal tubules), a better measure of intravascular dehydration and diuretic resistance than creatinine [9]. Serum urea also rises with increased protein catabolism due to worsening HF, infection or reduced dietary protein [22].

Urea may be a better prognostic indicator because it incorporates the cumulative effects of several influences, including hemodynamic alterations that result in renal hypoperfusion, and the extent of neurohormonal activation that is closely associated with altered renal hemodynamics and the progression of left ventricular dysfunction. In decompensated $\mathrm{HF}$, the activation of the renin-angiotensinaldosterone system, increased catecholamine production, and elevated endothelin levels contribute to renal arteriolar vasoconstriction. The result is a reduction in renal perfusion pressure with increased sodium and water reabsorption that produces a parallel increase in urea reabsorption. The net result is reduced urea excretion and an elevation in plasma concentration level that is not solely due to the fall in GFR and therefore not associated with a proportional rise in serum creatinine level. Vasopressin also promotes the reabsorption of urea in the distal nephron, resulting in increased plasma levels [14]. In advanced HF, the more frequent use of high-dose diuretics and angiotensin-converting enzyme inhibitor/angiotensin receptor blocker therapy may potentially contribute to increases in urea. Muscle wasting and cachexia in patients with advanced HF may also increase urea. This may explain why urea may serve as a more encompassing biomarker by reflecting the interplay between cardiovascular and renal dysfunctions, serving as a potential surrogate for the increasing use of drugs that affect renal function and for systemic wasting as a result of advancing HF [12].

Absolute increases in creatinine also performed well. The incidence of WRF was lower when using this definition, with fewer patients identified as having WRF and, consequently, a worse prognosis. These data reflect a higher specificity of creatinine regarding its prognostic information.

As previously stated, WRF defined by an absolute increase in creatinine may be biased by baseline renal function secondary to the exponential relationship between creatinine and renal function. To some authors, a relative change in eGFR may describe better the physiology relevant to WRF [18]. Accordingly, we also accounted for absolute variations and relative changes in eGRF, although their predictive value regarding prognosis was lower. A possible explanation may result from the relatively preserved values of renal function at baseline (mean eGFR $63.2 \pm 21.5 \mathrm{ml} / \mathrm{min} / 1.73 \mathrm{~m}^{2}$; only $10 \%$ of the patients with eGFR $\leq 35.9 \mathrm{ml} / \mathrm{min} / 1.73 \mathrm{~m}^{2}$ ) and higher proportions of patients in the lower NYHA classes (I and II) in our sample. According to previous studies, all formulas underestimate the true glomerular filtration rate in the near-normal values of renal function $[23,24]$. When the estimated renal function is $>65.0 \mathrm{ml} / \mathrm{min} / 1.73 \mathrm{~m}^{2}$ the true renal function is in fact higher. Also, the bias is increased in all formulas when used in patients with mild chronic HF [23]. It is possible that in our patients the true renal function was in fact underestimated, which may have reflected a less severe prognosis when defining WRF according to the Modification of Diet in Renal Disease formula.

The markers of WRF we used are inexpensive, easily accessible and commonly seen in daily routine medical practice, making them valuable and affordable tools for prognostic evaluation in HF patients. Other potential markers of renal dysfunction, such as serum cystatin-C or Neutrophil Gelatinase-associated Lipocalin, were not used. According to some studies, serum cystatin $C$ is more sensitive in identifying mild reductions in kidney function than serum creatinine alone $[25,26]$, although its levels may be affected by many factors other than GFR [27, 28]. Neutrophil Gelatinase-associated Lipocalin has been tested as an early recognition marker of acute kidney injury after cardiac surgery and in patients with acute HF [29,30], although the available evidence regarding it as a predictor of outcomes in cardiovascular disease is very limited [31].

\subsection{Strengths and limitations}

The main strengths of this study are to provide additional information regarding the effect of WRF on long-term all-cause death and hospital admission for HF, in ambulatory HF patients. Compared to previous 

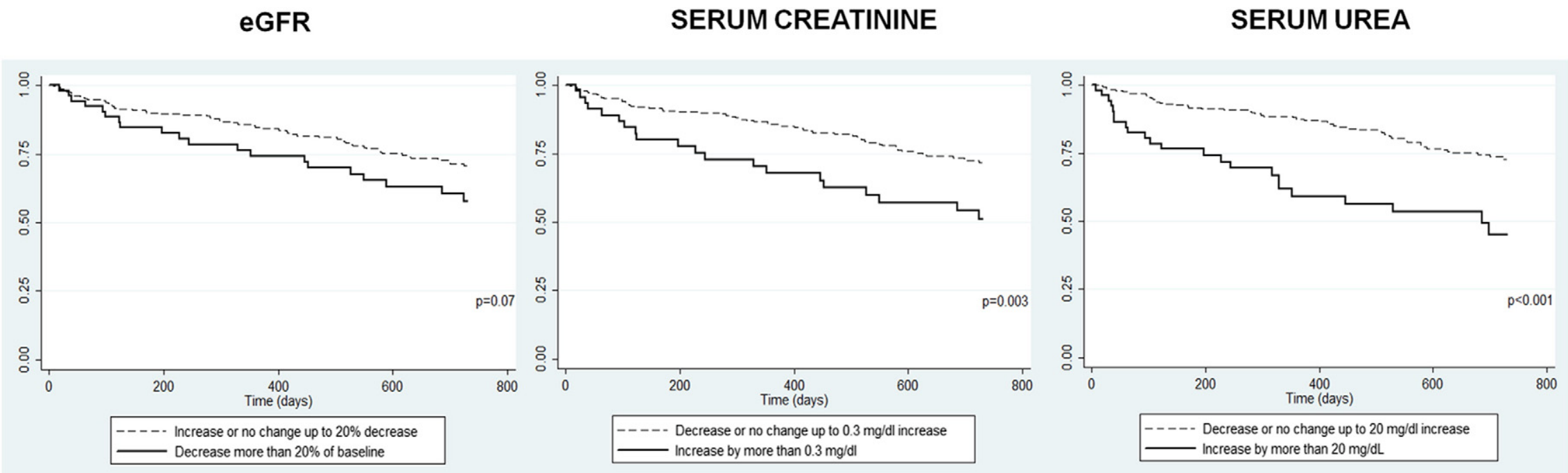

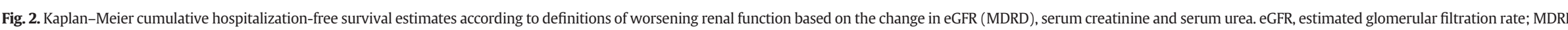
Modification of Diet in Renal Disease. 
studies on this matter, this study adds a fair comparison among different definitions of WRF by applying standardized criteria and comparing them all in the same patients. Also, since WRF is a dynamic concept, reflecting the change in renal function over time, we fixed the period over which this change was being considered to improve comparability among patients of the cohort.

The authors acknowledge several limitations in this study. Data were analyzed only at two defined points during follow-up. Factors that could affect the renal function in the intervening periods such as hospitalizations, medications, dehydration, or exposure to intravenous contrast were not taken into account. Patients who had incomplete data sets at the baseline or follow-up were not included in the analysis, potentially introducing bias. Nevertheless, patients excluded from the analysis were similar to our study sample regarding potential confounders and risk of death or HF hospitalization, as previously stated, minimizing the concern with these exclusions. Other cardiorenal markers such as BNP/NT-proBNP measures [32] were not included in the multivariate model as potential confounders because of their unavailability for a long time in a large part of the study sample. The retrospective design, avoiding changes in practice due to study participation, contributes to a closer approximation to the real-life prognostic performance of these risk markers.

\section{Learning points}

- WRF is associated with a clinically relevant worse outcome.

- Serum creatinine and urea represent powerful, inexpensive, simple and accessible markers of prognosis in ambulatory HF patients.

\section{Conclusion}

In ambulatory HF patients, WRF was associated with a clinically relevant worse outcome, independently of important confounders. The most informative WRF definitions in terms of HF prognosis were based on an increase in serum creatinine or in serum urea, more than the decrease in an estimate of glomerular filtration rate. Serum creatinine and urea represent powerful, inexpensive, simple and accessible markers of prognosis.

\section{Conflict of interests}

The authors state that they have no conflicts of interest.

\section{Acknowledgments}

A grant from FCT (PTDC/SAU-ESA/107940/2008) is gratefully acknowledged.

\section{References}

[1] Aronson D. Cardiorenal syndrome in acute decompensated heart failure. Expert Rev Cardiovasc Ther 2012;10:177-89.

[2] Bock JS, Gottlieb SS. Cardiorenal syndrome: new perspectives. Circulation 2010;121:2592-600

[3] House AA. Cardio-renal syndrome type 4: epidemiology, pathophysiology and treatment. Semin Nephrol 2012;32:40-8.

[4] Chuasuwan A, Kellum JA. Cardio-renal syndrome type 3: epidemiology, pathophysiology, and treatment. Semin Nephrol 2012;32:31-9.

[5] Maeder MT, Rickli H, Pfisterer ME, Muzzarelli S, Ammann P. Fehr T, et al. Incidence, clinical predictors, and prognostic impact of worsening renal function in elderly patients with chronic heart failure on intensive medical therapy. Am Heart J 2012;163:407-14 [14 e1].

[6] Knight EL, Glynn RJ, McIntyre KM, Mogun H, Avorn J. Predictors of decreased renal function in patients with heart failure during angiotensin-converting enzyme inhibitor therapy: results from the studies of left ventricular dysfunction (SOLVD). Am Heart J 1999; 138:849-55.

[7] Dickstein K, Cohen-Solal A, Filippatos G, McMurray JJ, Ponikowski P, Poole-Wilson PA, et al. Guidelines ESCCfP. ESC guidelines for the diagnosis and treatment of acute and chronic heart failure 2008: the Task Force for the Diagnosis and Treatment of Acute and Chronic Heart Failure 2008 of the European Society of Cardiology. Developed in collaboration with the Heart Failure Association of the ESC (HFA) and endorsed by the European Society of Intensive Care Medicine (ESICM). Eur Heart J 2008;29:2388-442.

[8] Hillege HL, Nitsch D, Pfeffer MA, Swedberg K, McMurray JJ, Yusuf S, et al. Renal function as a predictor of outcome in a broad spectrum of patients with heart failure. Circulation 2006;113:671-8.

[9] Cleland JG, Carubelli V, Castiello T, Yassin A, Pellicori P, Antony R. Renal dysfunction in acute and chronic heart failure: prevalence, incidence and prognosis. Heart Fail Rev 2012;17:133-49.

[10] Crespo-Leiro MG, Delgado JF, Paniagua MJ, Vazquez de Prada JA, Fernandez-Yanez J Almenar L, et al. Prevalence and severity of renal dysfunction among 1062 heart transplant patients according to criteria based on serum creatinine and estimated glomerular filtration rate: results from the CAPRI study. Clin Transpl 2010 Jul-Aug;24:E88-93.

[11] Levey AS, Bosch JP, Lewis JB, Greene T, Rogers N, Roth D. A more accurate method to estimate glomerular filtration rate from serum creatinine: a new prediction equation. Modification of Diet in Renal Disease Study Group. Ann Intern Med 1999;130:461-70.

[12] Cauthen CA, Lipinski MJ, Abbate A, Appleton D, Nusca A, Varma A, et al. Relation of blood urea nitrogen to long-term mortality in patients with heart failure. Am J Cardiol 2008;101:1643-7.

[13] Filippatos G, Rossi J, Lloyd-Jones DM, Stough WG, Ouyang J, Shin DD, et al. Prognostic value of blood urea nitrogen in patients hospitalized with worsening heart failure: insights from the Acute and Chronic Therapeutic Impact of a Vasopressin Antagonist in Chronic Heart Failure (ACTIV in CHF) study. J Card Fail 2007;13:360-4.

[14] Aronson D, Mittleman MA, Burger AJ. Elevated blood urea nitrogen level as a predictor of mortality in patients admitted for decompensated heart failure. Am J Med 2004;116:466-73.

[15] Ronco C, Haapio M, House AA, Anavekar N, Bellomo R. Cardiorenal syndrome. J Am Coll Cardiol 2008;52:1527-39.

[16] Damman K, Navis G, Voors AA, Asselbergs FW, Smilde TD, Cleland JG, et al. Worsening renal function and prognosis in heart failure: systematic review and metaanalysis. J Card Fail 2007;13:599-608.

[17] McAlister FA, Ezekowitz J, Tonelli M, Armstrong PW. Renal insufficiency and heart failure: prognostic and therapeutic implications from a prospective cohort study Circulation 2004:109:1004-9.

[18] Testani JM, McCauley BD, Chen J, Shumski M, Shannon RP. Worsening renal function defined as an absolute increase in serum creatinine is a biased metric for the study of cardio-renal interactions. Cardiology 2010;116:206-12.

[19] Testani JM, Kimmel SE, Dries DL, Coca SG. Prognostic importance of early worsening renal function after initiation of angiotensin-converting enzyme inhibitor therapy in patients with cardiac dysfunction. Circ Heart Fail 2011;4:685-91.

[20] Damman K, Jaarsma T, Voors AA, Navis G, Hillege HL, van Veldhuisen DJ, Investigators $C$. Both in- and out-hospital worsening of renal function predict outcome in patients with heart failure: results from the Coordinating Study Evaluating Outcome of Advising and Counseling in Heart Failure (COACH). Eur J Heart Fail 2009;11:847-54.

[21] Brandimarte F, Vaduganathan M, Mureddu GF, Cacciatore G, Sabbah HN, Fonarow GC, et al. Prognostic implications of renal dysfunction in patients hospitalized with heart failure: data from the last decade of clinical investigations. Heart Fail Rev 2013;18:167-76

[22] Lin HJ, Chao CL, Chien KL, Ho YL, Lee CM, Lin YH, et al. Elevated blood urea nitrogento-creatinine ratio increased the risk of hospitalization and all-cause death in patients with chronic heart failure. Clin Res Cardiol 2009;98:487-92.

[23] Smilde TD, van Veldhuisen DJ, Navis G, Voors AA, Hillege HL. Drawbacks and prognostic value of formulas estimating renal function in patients with chronic heart failure and systolic dysfunction. Circulation 2006;114:1572-80.

[24] Lin J, Knight EL, Hogan ML, Singh AK. A comparison of prediction equations for estimating glomerular filtration rate in adults without kidney disease. J Am Soc Nephrol 2003; $14: 2573-80$.

[25] Hoek FJ, Kemperman FA, Krediet RT. A comparison between cystatin C, plasma creatinine and the Cockcroft and Gault formula for the estimation of glomerular filtration rate. Nephrol Dial Transplant 2003;18:2024-31.

[26] Dharnidharka VR, Kwon C, Stevens G. Serum cystatin C is superior to serum creatinine as a marker of kidney function: a meta-analysis. Am J Kidney Dis 2002;40:221-6.

[27] Macdonald J, Marcora S, Jibani M, Roberts G, Kumwenda M, Glover R, et al. GFR estimation using cystatin $C$ is not independent of body composition. Am J Kidney Dis 2006:48:712-9.

[28] Knight EL, Verhave JC, Spiegelman D, Hillege HL, de Zeeuw D, Curhan GC, et al. Factors influencing serum cystatin $C$ levels other than renal function and the impact on renal function measurement. Kidney Int 2004;65:1416-21.

[29] Ronco C, Cruz D, Noland BW. Neutrophil gelatinase-associated lipocalin curve and neutrophil gelatinase-associated lipocalin extended-range assay: a new biomarker approach in the early diagnosis of acute kidney injury and cardio-renal syndrome. Semin Nephrol 2012;32:121-8.

[30] Mishra J, Dent C, Tarabishi R, Mitsnefes MM, Ma Q, Kelly C, et al. Neutrophil gelatinase-associated lipocalin (NGAL) as a biomarker for acute renal injury after cardiac surgery. Lancet 2005;365:1231-8.

[31] Cruz DN, Gaiao S, Maisel A, Ronco C, Devarajan P. Neutrophil gelatinase-associated lipocalin as a biomarker of cardiovascular disease: a systematic review. Clin Chem Lab Med 2012;50:1533-45.

[32] Carr SJ, Bavanandan S, Fentum B, Ng L. Prognostic potential of brain natriuretic peptide (BNP) in predialysis chronic kidney disease patients. Clin Sci (Lond) 2005;109:75-82. 